Welfare and Nursing Studies

\title{
Hubungan Dukungan Suami Terhadap Peningkatan Akseptor KB Suntik di Wilayah Kerja Puskesmas Segeri Kabupaten Pangkep
}

\author{
Susi Sastika Sumi ${ }^{1}$, Ratna $^{1}$ \\ ${ }^{1}$ STIKES Nani Hasanuddin Makassar. Sulawesi Selatan, Indonesia.
}

\section{Article History \\ Received: \\ 05.02.2020}

Revised:

14.03 .2020

Accepted:

10.04.2020

*Corresponding Author:

Susi Sastika Sumi

Email:

susisastikasumi@yahool.co.id

This is an open access article, licensed under: $\mathrm{CC}-\mathrm{BY}-\mathrm{SA}$
Abstrak: Perkembangan Pertumbuhan jumlah penduduk di dunia setiap tahun terus meningkat, keluarga berencana telah digambarkan sebagai alat yang kuat untuk mengurangi angka pertumbuhan jumlah penduduk, terutama dinegara-negara dengan tingkat pertumbuhan populasi yang tinggi dan prevalensi kontrasepsi yang rendah. Tujuan penelitian ini yaitu untuk mengetahui hubungan dukungan suami terhadap peningkatan akseptor KB suntik di Wilayah Kerja Puskesmas Segeri Kabupaten Pangkep. Penelitian ini menggunakan jenis penelitian kuantitatif dengan metode penelitian survey analytic dilakukan dengan rancangan cross sectional. Pengambilan sampel menggunakan teknik non-probability sampling yaitu purposive sampling dan jumlah sampel sebanyak 80 responden. Pengumpulan data menggunakan kuesioner. Data dianalisis menggunakan program SPSS dengan uji stastistik Chi-Squaredan tingkat kemaknaan $\rho$ Value $<0,05$. Berdasarkan hasil analisis hubungan dukungan suami terhadap peningkatan akseptor KB suntik diperoleh nilai $\rho=0,037$ berarti ada hubungan bermakna antara dukungan suami dengan peningkatan akseptor KB suntik. Kesimpulan dalam penelitian ini adalah terdapat hubungan dukungan suami terhadap peningkatan akseptor KB suntik di Wilayah Kerja Puskesmas Segeri Kabupaten Pangkep. Diharapkan adanya penginkatan edukasi kepada pasangan usia subur untuk ketepatan dalam pemilihan alat kontrasepsi.

Kata Kunci: Dukungan Suami, KB Suntik, Kesehatan.

The Relationship of Husband's Support to the Improvement of Contraception Injection Acceptor in Puskesmas Segeri Kabupaten Pangkep

Abstract: Growth in the world's population continues to increase every year, family planning has been described as a powerful tool to reduce population growth rates, especially in countries with high population growth rates and low contraceptive prevalence. The purpose of this study was to determine the relationship of husband's support to the increase in injecting family planning acceptors in the work area of Puskesmas Segeri Kabupaten Pangkep. This study uses quantitative research with analytic survey research methods conducted with cross sectional design. Sampling using non-probability sampling techniques, namely purposive sampling and a total sample of 80 respondents. Data collection using a questionnaire. Data were analyzed using the SPSS program with Chi-Squared statistical tests and the significance level $\rho$ Value $<0.05$. Based on the analysis of the relationship between husband's support and the increase in injecting KB acceptors, the value $\rho=0.037$ means that there is a significant relationship between husband support and an increase in injecting $\mathrm{KB}$ acceptors. The conclusion of this research is that there is a relationship between husband's support and the increase in injecting family planning acceptors in the work area of Puskesmas Segeri Kabupaten Pangkep. It is expected that there will be an increase in education for couples of childbearing age for accuracy in the selection of contraceptives.

Keywords: Contraception Injection, Health, Husband Support. 


\section{Pendahuluan}

Pertumbuhan jumlah penduduk di dunia setiap tahun terus meningkat, hal ini dapat dilihat dari data estimasi jumlah penduduk di dunia tahun 2017 sebanyak 7.550 milyar jiwa, tahun 2018 sebanyak 7.632 milyar jiwa dan tahun 2019 sebanyak 7.714 milyar jiwa. Berdasarkan data World Population 2019 jumlah penduduk terbanyak ditempati oleh China dengan jumlah penduduk 1.419 milyar jiwa, urutan ke dua ditempati oleh India dengan jumlah penduduk 1.366 milyar kemudian disusul oleh Amerika Serikat dengan jumlah penduduk 328 jiwa dan diurutan k-4 oleh Indonesia yaitu sekitar 269 juta jiwa [1].

Keluarga berencana telah digambarkan sebagai alat yang kuat untuk mengurangi angka pertumbuhan jumlah penduduk, terutama di negara-negara dengan tingkat pertumbuhan populasi yang tinggi dan prevalensi kontrasepsi yang rendah. Menurut survei di negara berpenghasilan rendah dan menengah, jumlah wanita yang ingin menghindari konsepsi dan karena itu membutuhkan kontrasepsi yang efektif adalah 867 juta (57\%) pada tahun 2012 [2].

Menurut World Health Organization (WHO) 2018, secara global penggunaan kontrasepsi modern sedikit meningkat, dari 54\% pada tahun 1990 menjadi 57,4\% pada tahun 2015 . Persentase peserta KB aktif pasangan usia subur di Indonesia pada tahun 2016 sebesar 74,8\%. Data dari 33 provinsi, ada 15 provinsi yang presentasenya masih berada di bawah presentase nasional, salah satunya adalah Provinsi Sulawesi Selatan yang memiliki presentase sebesar 72,30\% [3].

Berdasarkan data yang diperoleh dari Puskesmas Segeri Kabupaten Pangkep pengguna KB suntik meningkat, pada tahun 2019 sejak bulan 2017 dan 2018 tercatat memiliki PUS sebanyak 993. Pengguna KB aktif dari 64,9\% pada tahun 2017 menjadi 80,1\% pada tahun 2018, sedangkan pengguna KB baru dari 38,0\% pada tahun 2017 menjadi 69,8\% pada tahun 2018 dan pada tahun 2019 bulan Maret tercatat jumlah pasangan usia subur sebanyak 1.036. Peserta KB aktif menggunakan KB suntik sebanyak $505(48,7 \%)$, pil sebanyak $121(11,7 \%)$, implan sebanyak $13(1,3 \%)$, MOW sebanyak $10(0,9 \%)$, IUD sebanyak $7(0,6 \%)$, dan tidak ada yang menggunakan metode kontrasepsi kondom dan MOP. Setelah dilakukan wawancara pada 6 ibu akseptor KB suntik, 4 diantaranya memilih KB suntik dengan alasan bahwa pemakaiannya praktis, ekonomis, tidak perlu melalui proses trauma, serta suami meminta karena tidak mengganggu kenyamanan saat melakukan senggama. Hal ini turut melatar belakangi penulis untuk melakukan penelitian tentang hubungan dukungan suami terhadap peningkatan akseptor KB suntik di Wilayah Kerja Puskesmas Segeri Kabupaten Pangkep.

\section{Bahan dan Metode}

\subsection{Lokasi, Populasi, Sampel}

Penelitian ini dilaksanakan di Wilayah Kerja Puskesmas Segeri Kabupaten Pangkep pada tanggal 24 Oktober s/d 25 November 2019. Populasi dalam penelitian ini adalah seluruh seluruh ibu akseptor KB yang ada di Wilayah Kerja Puskesmas Segeri Kabupaten Pangkep sebanyak 505 orang dengan jumlah sampel pada penelitian ini adalah 80 orang.

1. kriteria inklusi:

a. Ibu akseptor KB yang berada di wilayah kerja Puskesmas Segeri Kabupaten Pangkep.

b. Ibu akseptor KB yang bersedia untuk menjadi responden.

2. kriteria eksklusi:

a. Ibu yang sudah menopause.

b. Ibu yang mengalami kecatatan mental dan fisik (depresi, tuna rungu, buta huruf, tuna netra, dan tuna wicara).

\subsection{Pengumpulan Data}

Pengumpulan data meliputi [4]:

1. Data sekunder adalah data yang diperoleh dalam bentuk jadi dan telah diolah oleh pihak lain yang biasanya dalam bentuk publikasi.

2. Data primer adalah data yang dikumpulkan dan diolah sendiri oleh suatu organisasi atau perorangan langsung dari objeknya.

\subsection{Pengolahan Data}

Proses pengolahan data meliputi [5]:

1. Editing

Editing adalah upaya untuk memeriksa kembali kebenaran data yang diperoleh atau dikumpulkan.

Editing dapat dilakukan pada tahap pengumpulan data atau setelah data terkumpul. 
2. Coding

Coding merupakan kegiatan pemberian kode numerik (angka) terhadap data yang terdiri atas kategori.

3. Entry

Data entri adalah kegiatan memasukkan data yang telah dikumpulkan kedalam master tabel atau atau data base komputer, kemudian membuat distribusi (frekuensi sederhana atau bisa juga dengan membuat tabel kontigensi.

4. Tabulasi

Membuat tabel- tabel data, sesuai dengan tujuan penelitian atau yang diinginkan oleh peneliti. (Hidayat, 2014).

\subsection{Analisis Data}

Analisa data meliputi:

1. Analisis Univariat

Digunakan untuk mendeskripsikan variabel penelitian guna memperoleh gambaran atau karakteristik sebelum dilakukan analisi bivariat. Hasil dari penelitian ditampilkan dalam bentuk distribusi frekuensi.

2. Analisis Bivariat

Analisis bivariat yang dilakukan adalah tabulasi silang antara dua variabel yaitu variabel independen dan dependen. Analisis bivariat yang digunakan untuk mengetahui hubungan terhadap objek penelitian adalah menggunakan uji chi square.

\section{Hasil Penelitian}

Berikut hasil penelitian ini, adalah:

\subsection{Analisis Univariat}

Tabel 1 menunjukkan dari 80 responden lebih banyak responden yang berada pada rentang usia 20-35 tahun, yaitu sebanyak 54 orang $(67,5 \%)$, dan yang berusia antara 36-45 tahun yaitu sebanyak 26 orang $(33,5 \%)$. Berdasarkan tingkat pendidikan yang paling banyak adalah yang berpendidikan rendah (tidak sekolah, tamat SD, dan tamat SMP) yaitu sebanyak 54 orang $(67,5 \%)$, dan yang berpendidikan tinggi (SMA dan Akademi/PT) yaitu sebanyak 26 orang (33,5\%). Berdasarkan lama penggunaan KB paling banyak responden baru menggunakan di bawah 1 tahun hingga 1 tahun yang berjumlah 41 orang $(51,2 \%)$, responden yang sudah menggunakan diatas 1 tahun berjumlah 39 orang $(48,8 \%)$.

Tabel 1. Distribusi karakteristik responden di Wilayah Kerja Puskesmas Segeri Kabupaten Pangkep 2019. $(n=80)$

\begin{tabular}{ccc}
\hline Karakteristik & $\mathbf{n}$ & $\mathbf{\%}$ \\
\hline Usia & & \\
20-35 tahun & 54 & 67,5 \\
$36-45$ tahun & 26 & 33,5 \\
\hline Pendidikan & & \\
Pendidikan rendah & 54 & 67,5 \\
Pendidikan tinggi & 26 & 33,5 \\
\hline Lama penggunaan KB & & \\
$\leq 1$ tahun & 41 & 51,2 \\
$>1$ tahun & 39 & 48,8 \\
\hline
\end{tabular}

\subsection{Analisis Bivariat}

Berdasarkan Tabel 2, diketahui dari jumlah 73 (91,2\%) responden lebih banyak responden dengan dukungan suami baik yang menggunakan KB suntik yaitu sebanyak 52 orang $(65,0 \%)$ dari pada yang 
menggunakan $\mathrm{KB}$ jenis lain yaitu 21 orang $(62,2 \%)$. Sedangkan dari jumlah 7 responden $(8,8 \%)$ dengan dukungan suami kurang lebih banyak yang menggunakan KB jenis lain yaitu sebanyak 6 orang $(7,5 \%)$ dari pada yang menggunakan KB suntik yaitu 1 orang $(1,2 \%)$.

Tabel 2. Hubungan antara Dukungan Suami dengan Peningkatan Akseptor KB Suntik di Wilayah Kerja Puskesmas Segeri Kabupaten Pangkep 2019

\begin{tabular}{|c|c|c|c|c|c|c|}
\hline \multirow{3}{*}{$\begin{array}{c}\text { Dukungan } \\
\text { Suami }\end{array}$} & \multicolumn{4}{|c|}{ Akseptor KB } & \multirow{2}{*}{\multicolumn{2}{|c|}{ Total }} \\
\hline & \multicolumn{2}{|c|}{ KB Suntik } & \multicolumn{2}{|c|}{ KB Jenis Lain } & & \\
\hline & $\mathrm{n}$ & $\%$ & $\mathrm{n}$ & $\%$ & $\mathrm{n}$ & $\%$ \\
\hline Kurang & 1 & 1,2 & 6 & 7,5 & 7 & 8,8 \\
\hline Baik & 52 & 65,0 & 21 & 62,2 & 73 & 91,2 \\
\hline Total & 58 & 72,5 & 22 & 27,5 & 80 & 100,0 \\
\hline & & & $p=0$ & & & \\
\hline
\end{tabular}

Setelah dilakukan analisis menggunakan uji Chi Square, diperoleh pvalue sebesar $0.037<\alpha 0.05$, dengan demikian dalam penelitian ini diterima, dan dapat dinyatakan ada hubungan dukungan suami terhadap peningkatan akseptor KB di Wilayah Kerja Puskesmas Segeri Kabupaten Pangkep.

\section{Pembahasan}

Hubungan dukungan suami terhadap peningkatan akseptor KB di Wilayah Kerja Puskesmas Segeri Kabupaten Pangkep

Berdasarkan hasil penelitian yang dilakukan, maka diketahui bahwa dari total $73(91,2 \%)$ responden lebih banyak responden dengan dukungan suami baik yang menggunakan $\mathrm{KB}$ suntik yaitu sebanyak 52 orang $(65,0 \%)$ dari pada yang menggunakan KB jenis lain yaitu 21 orang $(62,2 \%)$. Sedangkan dari jumlah 7 responden $(8,8 \%)$ dengan dukungan suami kurang lebih banyak yang menggunakan KB jenis lain yaitu sebanyak 6 orang $(7,5 \%)$ dari pada yang menggunakan KB suntik yaitu 1 orang $(1,2 \%)$.

Setelah dilakukan analisis menggunakan uji Chi Square, diperoleh pvalue sebesar $0.037<\alpha 0.05$, dengan demikian dalam penelitian ini diterima, dan dapat dinyatakan ada hubungan dukungan suami terhadap peningkatan akseptor KB di Wilayah Kerja Puskesmas Segeri Kabupaten Pangkep.

Penilitian ini sejalan dengan penelitan yang dilakukan oleh (Trimuriani \& Widyaningsih, 2017) tentang hubungan dukungan suami dengan penggunaan kontrasepsi suntik di Desa Bulungcangkring dengan jumlah responden 109 dimana yang mendapatkan dukungan suami dalam menggunakan kontrasepsi sebanyak $87(79,8 \%)$ responden, sedangkan $22(20,2 \%)$ responden tidak mendapatkan dukungan dari suami.

Hasil penelitian tersebut juga sejalan dengan penelitian yang dilakukan oleh (Revina, et al 2017) menunjukkan bahwa dari data analisis diperoleh 91 responden, responden yang berdasarkan Dukungan Suami yang mendukung 63 (50,8\%) dan responden yang berdasarkan Dukungan Suami yang tidak mendukung dan memilihsebanyak 28 responden $(49,2 \%)$ maka hasil tersebut dapat ditarik kesimpulan bahwa dukungan suami berpengaruh dengan Pemilihan Kontrasepsi Suntik Pada Akseptor KB di Kelurahan Panasakan Kecamatan Baolan Kabupaten Tolitoli.

Mularsih, dkk [7] mengatakan dukungan suami adalah dukungan yang diberikan oleh suami dalam bentuk verbal dan non-verbal, saran, bantuan yang nyata berupa tingkah laku atau kehadiran yang dapat memberikan keuntungan emosional dan mempengaruhi tingkah laku istrinya.

Dukungan suami biasanya berupa perhatian dan memberikan rasa nyaman serta percaya diri dalam mengambil keputusan tersebut dalam pemilihan kontrasepsi [8]. Kurangnya dukungan suami yang diberikan akan mempengaruhi kepercayaan diri istri untuk memilih kontrasepsi yang ingin digunakan. Suami yang merupakan kepala keluarga harus bijak dalam mengambil keputusan, baik keluarganya termasuk istrinya [9]. Untuk memilih kontrasepsi yang akan digunakan, seorang wanita (istri) tentunya sangat membutuhkan pendapat dan dukungan dari pasangan (suami) [10].

Berdasarkan teori yang telah dikemukakan diatas dan hasil penelitian, maka peneliti berpendapat dimana sesuai hasil penelitian ini bahwa ada hubungan dukungan suami terhadap peningkatan akseptor KB suntik. 


\section{Kesimpulan}

Ada hubungan dukungan suami terhadap peningkatan akseptor KB suntik di wilayah kerja Puskesmas Segeri Kabupaten Pangkep.

Beberapa saran dari penelitian ini, adalah:

1. Bagi keluarga, kiranya berperan aktif dalam mengawasi, membimbing, dan memberikan dukungan dan motivasi agar ibu akseptor KB dapat mengatur jarak kehamilannya dengan baik.

2. Diharapkan adanya upaya untuk meningkatkan pengetahuan terkait alat kontrasepsi yang cocok sesuai dengan kebutuhan ibu akseptor KB.

3. Bagi peneliti selanjutnya, diharapkan kepada peneliti selanjutnya dapat meneliti lebih dalam dan lebih jauh lagi serta menggunakan analisis yang berbeda dan metode yang berbeda sehingga memperkaya analisis data penelitian serta penelitian ini dapat menjadi bahan dasar dalam penelitian selanjutnya dan menambahkan variabel independen laiannya yang berhubungan dengan peningkatan akseptor KB suntik.

\section{Daftar Pustaka}

[1] Worldometers. Worldometers, 2019. [Online]. Available:https://Www.Worldometers.Info/Wor ld-Population/ [Accessed: October 21, 2019].

[2] W. A. Fazraningtyas, A. Sari, and D. Rahmayani. Obstetrical Factors in Postpartum Depression: A Correlational Study at General Hospitals of Banjarmasin. International Journal of Clinical Inventions and Medical Sciences, vol. 2, no. 1, 2020.

[3] R. Kurniawan, Yudianto, B. Hardhana, and T. Sistawati, Eds Kemenkes RI. Profil Kesehatan Indonesia Tahun 2017. Jakarta: Kemenkes RI, 2018.

[4] A. A. Hidayat, Metode Penelitian Keperawatan dan Teknik Analisis Data. Jakarta: Salemba Medika, 2014.

[5] J. Kasim, R. Ratna, S. Suryani, and O. Suka. "Correlation between Post Natal Care and Premature Baby Health in the RSKD Ibu \& Anak Siti Fatimah Makassar". International Journal of Clinical Inventions and Medical Sciences, vol. 2, no. 1, 2020.

[6] Kemenkes RI. Riset Kesehatan Dasar; Riskesdas. Jakarta: Balitbang Kemenkes RI, 2013.

[7] S. Mularsih, L. Munawaroh, and D. Elliana, "Hubungan Pengetahuan Dan Dukungan Suami Dengan Pemilihan Alat Kontrasepsi Dalam Rahim (Akdr) Pada Pasangan Usia Subur (Pus) Di Kelurahan Purwoyoso Kecamatan Ngaliyan Kota Semarang," Jurnal Kebidanan, 2018 [Online]. Available: https://Doi.Org/1026714/Jk7220181441542018 [Accessed: October 21, 2019].

[8] Revina, J. Sakung, and F. Amalinda, "Hubungan Pengetahuan Dan Dukungan Suami Dengan Pemilihan Kontrasepsi Suntik Pada Akseptor Kb Di Kelurahan Panasakan Kecamatan Baolan Kabupaten Tolitoli," Jurnal Unismuh Palu, 2017.

[9] L. Trimuriani, and H. Widyaningsih, Hubungan Dukungan Suami Dengan Tingkat Kepuasan Pengguna Kontrasepsi Suntik Di Desa Bulucangkring Jekulo Kudus. Kudus: Publikasi Hasil Riset Kesehatan Untuk Daya Saing Bangsa, 2018.

[10] W. Pinamangan, R. Kundre, and Y. Bataha, "Hubungan Dukungan Suami Dengan Pemilihan Jenis Kontrasepsi Intra Uterine Device Pada Wanita Usia Subur Di Puskesmas Makalehi Kecamatan Siau Barat,” Jurnal Keperawatan, vol. 6, no. 2, 2018. 